\title{
The Future of Upper Extremity Rehabilitation Robotics: Research and Practice
}

Authors: Philip P. Vu PhD ${ }^{1,2}$, Cynthia A. Chestek, $\mathrm{PhD}^{1,3,4,5}$, Samuel R. Nason MS ${ }^{1}$, Theodore A. Kung $\mathrm{MD}^{2}$, Stephen W.P. Kemp PhD ${ }^{1,2}$, Paul S. Cederna $\mathrm{MD}^{1,2}$

\author{
Affiliations: \\ ${ }^{1}$ Department of Biomedical Engineering, University of Michigan, Ann Arbor, MI, USA. \\ ${ }^{2}$ Section of Plastic Surgery, University of Michigan, Ann Arbor, MI, USA. \\ ${ }^{3}$ Robotics Institute, University of Michigan, Ann Arbor, MI 48109, USA. \\ ${ }^{4}$ Department of Electrical Engineering and Computer Science, University of Michigan, Ann \\ Arbor, MI 48109, USA. \\ ${ }^{5}$ Neuroscience Graduate Program, University of Michigan, Ann Arbor, MI 48109, USA.
}

Acknowledgements: This work was supported by the National Institute of Neurological Disorders and Stroke under grant award number R01NS105132. Competing Interests: None of the authors has any conflict of interest to disclose. Ethical Statement: We confirm that we have read the Journal's position on issues involved in ethical publication and affirm that this report is consistent with those guidelines.

Number of words in abstract: 130

Number of words in manuscript: 4039

\section{Corresponding Author:}

Paul S. Cederna, MD

Chief, Section of Plastic Surgery

Robert Oneal Professor of Plastic Surgery

Professor, Department of Biomedical Engineering

This is the author manuscript accepted for publication and has undergone full peer review but has not been through the copyediting, typesetting, pagination and proofreading process, which may lead to differences between this version and the Version of Record. Please cite this article as doi: $10.1002 /$ mus. 26860

This article is protected by copyright. All rights reserved. 
University of Michigan

cederna@med.umich.edu

This article is protected by copyright. All rights reserved. 


\begin{abstract}
The loss of upper-limb motor function can have a devastating effect on people's lives. To restore upper-limb control and functionality, researchers and clinicians have developed interfaces to interact directly with the human body’s motor system. This review paper aims to provide detail of the peripheral nerve interfaces and brain machine interfaces that have been developed in the past 30 years for upper extremity control, and highlights the challenges that still remain to transition the technology into the clinical market. The findings from this review show that peripheral nerve interfaces and brain machine interfaces have many similar characteristics that enable them to be concurrently developed. Decoding neural information from both interfaces may lead to novel physiological models that may one day fully restore upper-limb motor function for a growing patient population.

Key Words: Peripheral nerve interfaces, Brain machine interfaces, Neuroprosthetics, Neural decoding, Electrophysiology, Rehabilitation robotics
\end{abstract}




\section{Introduction}

The sudden loss of motor function in the upper extremity can significantly alter a person's way of life, creating many new physical and emotional burdens that can last a lifetime. For the past 30 years, clinicians and engineers have worked together to treat patient populations most affected by upper extremity loss and functional deficits. Their main goal is to provide and restore intuitive control of the patient's own limb or an artificial limb. In the United Sates alone, approximately 2 million people live with limb loss with $~ 500,000$ people who have undergone upper-extremity amputations. ${ }^{1}$ In addition to this, the prevalence of spinal cord injury (SCI), an injury that impairs limb mobility, ranges from 249,000 to 363,000 persons with approximately 17,730 new SCI cases each year. ${ }^{2}$ Unfortunately, current clinical treatments for these problems are incapable of restoring full functional capabilities of an intact upper-limb. At most, people with amputations can be provided with simple prostheses, which unfortunately provide only basic or rudimentary movements. Similarly, rehabilitation can improve some hand function in people with SCIs at the cervical level, but falls short of providing full hand control. Among both populations, surveys have shown that restoration of hand function is the highest priority. 3,4

The past two decades have seen an acceleration in development of more articulated, lifelike prosthetic hands in the commercial sector. ${ }^{5-7}$ Despite these advancements, an appropriate prosthetic interface for the user to actively control all functionalities of the prosthesis in a natural and intuitive manner does not currently exist. The underlying problem for users not achieving

full autonomy of their prosthesis is the limited number of available control signals. ${ }^{8}$ Current control methods can only provide a finite number of movements, and insufficiently provide 
robust capabilities to control multiple independent finger movements. ${ }^{9}$ The control of multiple hand postures or movements with these basic controllers leads to unintuitive control, a prolonged learning curve, and lack of embodiment of the prosthesis.

To provide enhanced prosthetic control, researchers have focused their efforts on building better prosthetic interfaces. In particular, more invasive interfaces can gain access to more independent control sites, thus providing more intuitive fine motor control. Since the body's motor system generally remains intact outside of the injury site in both persons with amputations and paralysis, information about motor intent can be extracted and used to improve the control of advanced prostheses (Fig. 1). ${ }^{10-14}$ This review will focus on describing the pros and cons of these developing technologies for amputation and SCI, giving an overview of the different control strategies, and providing insight into the ways in which future research can expand these technologies to treat other populations with upper-extremity immobility.

\section{Myoelectric interfaces for amputation}

The human upper limb is composed of an intricate combination of muscles, tendons, and nerves providing people with fine motor control over their arms, fingers, and digits. Nerve fibers carry efferent motor action potentials which depolarize skeletal muscle fibers creating muscle contractions. Electromyography (EMG) signals can be recorded from muscles during voluntary contraction and can be used to control commercial myoelectric prostheses. Myoelectric prosthesis technology was first introduced in the 1950s. ${ }^{15}$ In the most basic setup, EMG is recorded from two muscle groups (agonist and antagonist muscle groups) with one or two 
surface electrodes placed on the skin. The recorded activity is then used to control one or two simple movements, e.g. hand open/close. This setup has been sufficiently reliable in a clinical setting, but fails to achieve multifunctional control of an upper extremity prosthetic device. ${ }^{9,16}$ Several factors regarding the characteristics of surface electrodes contribute to this limitation. ${ }^{8}$ Ideally, one surface electrode would record from one muscle to control a specific degree of freedom (i.e. index finger flexion), providing a one-to-one mapping of EMG activity to finger movement. However, in practice, surface electrodes record EMG activity from multiple nearby muscles creating cross-talk that consequently limits the number of independent signals available for multi-functional movements. Additionally, surface electrodes can lose contact due to shear forces, lose connectivity due to sweating, and can begin recording different control signals from skin shifting over the underlying muscle, which can alter the EMG signals and negatively impact the interpretation of the intended movement ${ }^{17,18}$.

Both hardware and software solutions have been proposed to mitigate electrode shift ${ }^{19-}$ 22. High-density surface EMG electrodes can cover a large surface area of the amputated limb, extracting a higher resolution of EMG signals and minimizing the electrode shift effect. In terms of software, Prahm et al. ${ }^{21}$, proposed an algorithm that first determines how much the electrode shifted during donning/doffing of the prosthetic hand, and then recalibrates the controller to compensate for the shift. Although these advances have shown progress in improving myoelectric technology, there still remains a fundamental problem. The number of available control sites is dependent on the presence of residual innervated muscles within the limb, e.g. 
fewer control sites exist for a transhumeral amputation than a transradial amputation. For a patient with a distal transradial amputation, there are many residual innervated muscles which can provide a significant number of independent control signals. On the other hand, a patient with a transhumeral amputation will have no residual innervated muscles to provide control signals for wrist, hand, or finger control. In order to gain access to more control sites, interfacing directly with the peripheral nervous system is required.

\section{Peripheral Nerve Interfaces}

Even decades following amputation, the peripheral nervous system retains the ability to transmit volitional motor commands to the phantom limb. ${ }^{23,24}$ In theory, the peripheral nerve is a rich signal source that can provide the necessary number of control sites for intuitive prosthesis control. Over the past two decades, several peripheral nerve interface strategies have been developed. ${ }^{25,26}$ These methods are designed to record efferent motor signals directly from the nerve (extracellular action potentials from nerve fascicles) or on the surface of the nerve (electroneurogram (ENG) activity arising from populations of nerve fascicles). In order to gain access to these signals, peripheral nerve electrodes were engineered in two main categories, epineural and intraneural electrodes (Fig. 2). ${ }^{14}$ Epineural electrodes have contacts that wrap around the surface of the nerve or are placed on the surface of the nerve while intraneural electrodes have contacts that penetrate into the peripheral nerve. 
The most common epineural electrode is the cuff electrode, which has two or more contacts placed within a flexible material and wrapped around the nerve..$^{27,28}$ There are a few challenges with these types of peripheral nerve interfaces. Firstly, the ENG amplitudes are very small making it difficult to consistently record efferent motor action potentials directly from the nerves due to the small size of the signals and the electrical noise from motion, adjacent nerve firing, and adjacent muscle firing, creating an unfavorable signal-to-noise ratio (SNR). ${ }^{29,30}$ This situation becomes increasingly complicated as more biofouling of the electrode occurs over time creating a less favorable SNR. Secondly, ENG signal recording faces the same problems of cross-talk as surface EMG: recording neural activity from a population of fascicles instead of just a single fascicle. To address this, algorithms have been proposed to localize and separate ENG activity. ${ }^{31-33}$ More recently, these methods have been tested in long-term animal studies and show promise in separating and recovering nerve fascicle signal sources reliably. ${ }^{34,35}$ Further studies are warranted to show if these methods can be translated, and effectively utilized with human nerves. Another type of epineural electrode, the flat interface nerve electrode (FINE), wraps around the nerve and flattens the nerve so that the electrode contacts are in closer proximity to each of the individual fascicles. ${ }^{36}$ This design facilitates recording efferent motor action potentials more selectively from individual fascicles, without the need for a more invasive, intraneural approach. Overall, due to the difficulties in recording small efferent motor action potentials and unfavorable SNR, epineural electrodes have found more use as stimulating devices to provide tactile sensory feedback for prosthetic users. ${ }^{37}$ 
Intraneural electrodes, on the other hand, have had more success in recording higher amplitude signals because of their direct contact with nerve fascicles. Examples of intraneural electrodes include the longitudinal intrafascicular electrode (LIFE ${ }^{38}$ ), transverse intrafascicular multichannel electrode (TIME ${ }^{39}$ ), and the Utah slanted electrode array $\left(\mathrm{USEA}^{40}\right)$. The LIFE has been used in multiple human studies including: real-time control of grip force and elbow position, offline classification of three different grasps, and sensory percepts (i.e. tactile sensations) that are evoked with electrical stimulation. ${ }^{41-44}$. Comparably, the TIME and USEA have been used to provide sensory feedback to human patients during bi-directional prosthesis control tasks. ${ }^{45,46}$

Although intraneural electrodes have been heavily tested in human subjects, their expected longevity and durability are still uncertain. ${ }^{47}$ Previous studies have reported degradation in signal amplitude and increased electrode impedance in USEAs over the course of four weeks. ${ }^{48}$ Histological analysis has shown that inserting these electrode tips into the nerve causes an inflammatory response with an increase of macrophages surrounding and attached to the device. ${ }^{49}$ Unfortunately, studies on other types of intraneural electrodes have not characterized signal degradation to the same degree or over the same period of time. ${ }^{50,51}$ Recently, the USEA has been reported to be functional for up to 14 months, but mainly for electrical stimulation to produce tactile sensory feedback. ${ }^{46}$ Consequently, the signal recording robustness of intraneural electrodes still remains undetermined. Until durability and signal stability are demonstrated within human subjects, intraneural electrodes may find more use as stimulating devices similar to 
epineural electrodes, providing tactile and proprioceptive feedback to improve prosthetic performance. ${ }^{46}$

\section{Surgical methods to improve peripheral interfaces}

The challenges faced with epineural and intraneural electrodes have led some groups to devise alternative interfacing architectures that exploit surgical techniques. Targeted muscle reinnervation $\left(\mathrm{TMR}^{52}\right)$ is a surgical technique that reroutes a transected nerve into a partially denervated, intact muscle (Fig. 3a). After a few months, the nerve reinnervates the muscle, and the muscle is able to contract normally under the efferent commands from the rerouted nerve. This in turn transforms the intact muscle into a biological amplifier for the once severed nerve, creating a new myoelectric site for prosthesis control. A report in 2013 noted that more than 60 TMR procedures had been performed worldwide on shoulder disarticulation and transhumeral amputees. ${ }^{53}$ Since then, TMR has continued to gain popularity as a surgical option for patients with proximal amputations, as it has also been shown to treat neuroma and phantom limb pain. ${ }^{54}$ In the early days of TMR, a patient with bilateral shoulder disarticulations was able to control elbow position and either hand opening/closure or wrist rotation using simultaneous proportional control. ${ }^{52}$ In 2007, Zhou et al. combined TMR signals with pattern recognition techniques, enabling users to control up to seven hand and arm postures. ${ }^{55,56}$ More recently in 2017, a randomized clinical trial of eight TMR participants showed that pattern recognition control outperformed a dual-site differential direct control system using antagonistic muscle pairs. ${ }^{57}$ 
Although TMR has expanded the capabilities of traditional myoelectric interfaces to control more advanced prosthetic technology, the spatial distribution of the rerouted nerves is limited. The technique requires the whole nerve to be transferred to a whole muscle or a partially denervated muscle. Consequently, the maximum number of independent control sites is dependent on the number of transferred whole nerves. This limitation is reflected in clinical practice, where users are only able to control three to four basic movements. ${ }^{58}$ At more proximal levels of amputation, the organization of motor and sensory fascicles in the nerve are mixed. ${ }^{59}$ This makes differentiating the functions of the nerve during surgery more difficult, and does not guarantee representation of all functions at the reinnervation site.$^{60}$ Furthermore, TMR currently relies on surface electrodes for signal extraction, which can be challenging for all of the reasons previously mentioned.

The Regenerative Peripheral Nerve Interface (RPNI) peripheral nerve interface takes advantage of nerve and muscle regeneration to provide many distinct, unique control signals for high fidelity control of prosthetic devices. ${ }^{61-63}$ An RPNI is composed of a transected peripheral nerve, or peripheral nerve fascicle, that is implanted into a free muscle graft (Fig. 3b). The free muscle graft undergoes regeneration, revascularization, and reinnervation by the implanted peripheral nerve. ${ }^{64}$ An RPNI becomes a stable, peripheral nerve bioamplifier that is capable of producing high amplitude EMG signals. ${ }^{65-67}$ Previous work has shown that RPNIs can be successfully reinnervated and maintain a healthy electrical response up to 7 months postimplantation in rats ${ }^{65}$ and $20+$ months in non-human primates. ${ }^{67}$ Additionally, RPNIs exhibited 
electrical properties equivalent to intact muscle that can be utilized to control a prosthetic device. $^{67,68}$

A more recent study demonstrated that RPNIs are anatomically viable in humans, enabling long-term recording of efferent motor action potentials. ${ }^{69}$ Instead of using surface electrodes, intramuscular bipolar electrodes have been implanted directly into RPNIs to produce large signal-to-noise ratio (SNR) signals that have been used to control a prosthetic hand with high performance. ${ }^{69}$ In addition, dynamic ultrasound demonstrated RPNI contractions during attempted flexion of the phantom fingers of their hand. This was demonstrated in an aboveelbow amputation residual limb in which there were no long finger flexors or extensors to correspond with the attempted movement.

\section{Brain machine interfaces for spinal cord injury}

In contrast to amputation, spinal cord injury (SCI) leaves the musculature and peripheral nerves intact, but eliminates the patient's control over them. It has been shown that people with quadriplegia highly desire regaining upper extremity function and would prefer improved function of their own limb over use of an artificial limb. ${ }^{70,71}$ To achieve this goal, researchers have employed functional electrical stimulation (FES) of the non-functional muscles of the upper extremity to produce controlled movement. ${ }^{72}$ FES was originally described in the 1980 s and has been successful used to reanimate paralyzed limbs. ${ }^{73,74}$ Similar to controlling an advanced prosthesis, FES requires high fidelity control signals to control an intact limb. Early FES control systems have used either a physical switch ${ }^{75}$ or EMG control signals from intact, innervated 
muscles, post-SCI, to provide voluntary commands. ${ }^{76}$ This strategy can provide limited motor control signals to produce simple grasping movements. ${ }^{72}$ In order to harness more control signals to increase functionality, several groups have utilized cortical interfaces to extract control signals directly from the brain.

For the past 50 years, research groups have been recording and deciphering motor signals from the brain. Like myoelectric and peripheral nerve interfaces, there are several ways to extract neural activity (Fig. 4). The least invasive is electroencephalography (EEG), which uses surface electrodes that are placed on the scalp. EEG has been mainly used for assistive technology such as typing devices, ${ }^{77}$ but has more recently demonstrated capabilities of controlling a robotic hand. ${ }^{78} \mathrm{~A}$ more invasive technology is electrocorticography (ECoG), where electrodes are placed either above or below the dura mater layer. ${ }^{79}$ Successful control of arm and hand movements, a computer cursor, and a robotic hand using ECoG signals has been shown in a number of studies. ${ }^{80-85}$ Though progress has been made for these technologies, their main limitation is the effectiveness of the control signals. Similar to how surface electrodes record from a population of muscle activity, EEG and ECoG electrodes record from a population of brain activity from the motor cortex, making control of multiple independent movements challenging.

To gain access to more spatially specific signals and more detailed cortical information, intracortical electrodes have been developed to penetrate directly into the brain to record from individual or local groups of neurons. ${ }^{86-92}$ Studies have demonstrated the control of computer cursors and advanced prosthetic arms in three-dimensional space using these interfaces. ${ }^{13,93-95}$ 
There has also been great success in animating paralyzed musculature in non-human primates via FES controlled by the recorded neural activity. ${ }^{96-98}$ That success has translated to a clinical setting where two human case studies have demonstrated the ability of SCI patients to control grip force of paralyzed hands via FES delivered by surface electrodes ${ }^{99}$ or self-feed with the use

of implanted FES electrodes. ${ }^{100}$ In general, these studies have focused mainly on controlling only arm movements and hand grasps. Further studies are warranted to expand the control scheme to cover multi-digit functionality. In the past few years, there has been progress in this area with studies demonstrating control of individuated virtual finger movements in non-human primates. ${ }^{101,102}$ These promising results may one day enhance future FES systems and provide more dexterous hand control to SCI patients.

\section{Control methods}

Building an interface that effectively extracts intuitive signals for prosthesis or paralyzed upper-limb control represents one critical element to provide functional restoration. However, the interpretation of these signals and prediction of the user's intention is equally critical. Whether a subject is controlling a prosthesis or paralyzed limb, controllers can either function in a discrete or continuous mode (Fig. 5). ${ }^{9}$ In the case of hand function, discrete control means one of several hand postures is selected for execution. For example, in a simple on/off control scheme, the quiet period of neurological activity could represent a hand open state, whereas an amplitude or frequency of the neurological activity that is higher than some predetermined threshold could represent a hand closed state. This type of control scheme restricts the prosthetic 
hand to move at a pre-defined fixed velocity for both open and closed states. In the continuous mode, the change in signal amplitude or frequency over time could be used to control the velocity or force output of the hand. Defined as proportional control, modulation of one set of signals could control how fast the hand closes, and modulation of a second set could control how fast the hand opens. Unfortunately, both discrete and continuous methods become more difficult and unintuitive to use with increasing numbers of limb movements or degrees of freedom (DoF), mainly because the number of independent control sources are fewer than the increasing number of movement dimensions. ${ }^{8}$

To gain increased intuitive control of prosthetic or paralyzed limbs, researchers have focused their attention on pattern recognition algorithms as a possible replacement for conventional control. ${ }^{103}$ In this control scheme, multiple recording electrodes capture the natural generation of neural activity, which can be classified to a specific hand posture or grasp. ${ }^{103-105}$ As different patterns arise, multiple postures or complex movements can be classified. Users can then naturally switch between movements simply by thinking of moving to their desired posture, which would naturally activate the desired posture in their phantom limb or generate the relevant effector cortical signals. Multiple pattern recognition algorithms have been tested in laboratory settings. ${ }^{55,106,107}$ Researchers continue to test pattern recognition algorithms in both the laboratory and clinical setting, further improving the technology for conventional use. ${ }^{108}$ These algorithms have taken one step further in providing prosthesis users intuitive and natural control. However, this technique is characteristically discrete, meaning that only one posture can be 
chosen at a time, and users cannot proportionally control the speed of the prosthesis. This takes away the user's ability to control the amount of force being applied to an object, which may degrade functional performance. Although pattern recognition algorithms have become today's state-of-the-art controllers, they are still far from replicating the natural movements of the human hand.

In order to match the natural dexterity of the human hand, several groups have proposed using regression-based algorithms or continuous methods. ${ }^{109-113}$ Unlike pattern recognition, regression algorithms can use the rate of change in neurological activity to continuously and simultaneously estimate multiple control signals. Both peripheral nerve and brain interfaces have had success in implementing these algorithms for continuous control of multiple DoFs. ${ }^{13,102,113-}$ ${ }^{115}$ Although these algorithms show promise in accelerating the progress towards natural arm and hand control, there still remain some limitations. Regression controllers may not generalize well when performing functional tasks of daily living. This is because regression algorithms can only learn from the collected training data, and that data is typically gathered in a controlled laboratory environment. For example, perturbations from the external environment that were not included in the collected data are not understood by the regression controllers. Thus, when an external perturbation occurs on a prosthetic limb, the controller may fail in interpreting the user's intention, which may lead to a serious accident.

One approach that may generalize better is determining the true mathematical relationships between joint finger moments, muscle activations, and motor neuron spike trains 
from motor cortex. Upper-limb movement forces are generated from muscles innervated by pools of firing alpha motor neurons, ${ }^{116,117}$ which are generated directly from motor cortex. Studies have shown that EMG activity can be predicted from populations of neurons in motor cortex. ${ }^{118,119}$ Likewise, some groups have used neuromusculoskeletal modeling to understand the non-linear transformations between muscle activations and joint kinematics. ${ }^{120}$ These neuromusculoskeletal models have shown promise in providing continuous control for prosthesis users, but often these models need to be scaled and calibrated to an individual's limb shape, size, and EMG-force properties, which is impractical in a clinical setting. ${ }^{121}$ However, a more recent study has simplified the calibration process and achieved a robust, high performance prosthetic control. ${ }^{122}$ More physiological approaches may be warranted in order to regain intuitive and dexterous upper-limb control for both the amputation and SCI patient population.

On top of the algorithmic challenges shared between peripheral nerve and brain machine interfaces, the control signals extracted from motor cortex for brain machine interface prostheses are several synapses displaced from the end effector muscles. As a result, motor cortical recordings have an additional layer of abstraction in their relationship to muscular outputs. To combat this slight dissociation, several studies have tried to uncover the latent neural population dynamics that generate the recorded signals. ${ }^{123,124}$ In particular, groups have recently applied a deep learning solution called latent factor analysis via dynamical systems (LFADS) to use neural activity to accurately predict behavior in typical brain machine interface task paradigms. In addition to brain machine interface applications, LFADS have demonstrated the capability of 
predicting firing rates of untrained neurons across months and perturbations in neural state space corresponding to behavioral choices, suggesting the dynamics characteristic of LFADS may be accurately modeling the dynamics of neural populations. ${ }^{125,126}$ As promising as LFADS seems for bringing naturalistic brain machine interfaces closer to clinical use, its computational complexity is too great for a modern closed-loop, real-time system. Although being able to estimate latent neural states from samples of cortical neurons may allow more accurate estimations of a user's intent and greater prosthetic control, the algorithms are too computationally intense for modern real-time computational hardware to process in a clinical setting.

\section{Conclusion and future directions}

Acceleration in the development of peripheral nerve and brain machine interfaces have led to substantial improvements in patient care. However, there still remain many challenges before peripheral nerve and brain machine interfaces can be readily available for the clinical market. Further advances in these technologies will require additional studies in both animal models and human subjects. One such advancement is the development of portable systems which would allow the user to "leave the lab" and return to society using their assistive device (prosthetic limb or FES device). Currently, many of the systems mentioned above require the user to be tethered to several computers for signal processing, feature extraction, decoding, task management, data storage, and prosthesis control. Although many of those processing steps would only be required of a laboratory prosthesis, clinical prostheses still require powerful 
hardware for signal processing and decoding. Several recent research developments have attempted to tackle this issue, but necessary safety regulations have made translation of these devices to human use difficult. In the commercial sector, clinical systems for human implantation have been developed ${ }^{127}$, but do not yet have FDA approval.

Although progress is being made towards portable neural prostheses, patient populations with amputations and spinal cord injuries have articulated their desires to have fully implantable and integrated prosthetic devices. ${ }^{71}$ Several studies have developed implantable neuroprosthetic technologies for recording and wireless transmission of neural data, but these devices still require proximity to processing machines. ${ }^{128,129}$ A network of implantable electronic modules has been developed that is capable of recording EMG signals for prosthetic control and performing functional electrical stimulation (FES) for functional restoration in patients with paralysis. ${ }^{130}$ (Fig. 6). While this system is approved for limited use in humans, it continues to face the many challenges plaguing implantable devices. Hermetic sealing of the internal electronics while allowing a large quantity of feedthroughs to provide the many independent control signals required for a high dimensional prosthesis remains a major materials science and packaging challenge. Further, greater processing requirements generate more heat, which can be dangerous to tissue when implanted. Although wonderful strides are being made towards implantable prostheses, many engineering steps must be taken before their translation to clinical use. 


\section{References}

1. Ziegler-Graham K, MacKenzie EJ, Ephraim PL, Travison TG, Brookmeyer R. Estimating the Prevalence of Limb Loss in the United States: 2005 to 2050. Archives of Physical Medicine and Rehabilitation 2008; 89:422-429. Published online: March 1, 2008. DOI: 10.1016/j.apmr.2007.11.005.

2. National Spinal Cord Injuries Statistical Center. Spinal Cord Injry Facts and Figures at a Glance. 2019.

3. Snoek GJ, IJzerman MJ, Hermens HJ, Maxwell D, Biering-Sorensen F. Survey of the needs of patients with spinal cord injury: impact and priority for improvement in hand function in tetraplegics. Spinal Cord 2004; 42:526-532. Published online: September 2004. DOI: 10.1038/sj.sc.3101638.

4. Anderson KD, Fridén J, Lieber RL. Acceptable benefits and risks associated with surgically improving arm function in individuals living with cervical spinal cord injury. Spinal Cord 2009; 47:334-338. Published online: April 2009. DOI: 10.1038/sc.2008.148.

5. LUKE Arm Detail Page - Mobius Bionics. https://www.mobiusbionics.com/luke-arm/. Accessed February 11, 2020. 
6. Ottobock. Bebionic user guide. https://www.ottobockus.com/media/localmedia/prosthetics/upper-limb/files/14112_bebionic_user_guide_lo.pdf. Accessed February 11, 2020.

7. Touch Bionics. User brochure: i-limb quantum. https://www.touchbionics.com/sites/default/files/files/MA01374US\%20rev.\%202\%2C\%20 January\%202017\%20User\%20Brochure_i-limb\%20quantum.pdf. Accessed February 11, 2020.

8. Farina D, Jiang N, Rehbaum H, Holobar A, Graimann B, Dietl H, et al. The Extraction of Neural Information from the Surface EMG for the Control of Upper-Limb Prostheses: Emerging Avenues and Challenges. IEEE Transactions on Neural Systems and Rehabilitation Engineering 2014; 22:797-809. Published online: July 2014. DOI: 10.1109/TNSRE.2014.2305111.

9. Roche AD, Rehbaum H, Farina D, Aszmann OC. Prosthetic Myoelectric Control Strategies: A Clinical Perspective. Current Surgery Reports 2014; 2:1-11. Published online: January 25, 2014. DOI: 10.1007/s40137-013-0044-8.

10. Georgopoulos AP, Schwartz AB, Kettner RE. Neuronal population coding of movement direction. Science 1986; 233:1416-1419. Published online: September 26, 1986. DOI: 10.1126/science.3749885. 
11. Carmena JM, Lebedev MA, Crist RE, O’Doherty JE, Santucci DM, Dimitrov DF, et al. Learning to Control a Brain-Machine Interface for Reaching and Grasping by Primates. PLOS Biology 2003; 1:e42. Published online: October 13, 2003. DOI:

10.1371/journal.pbio.0000042.

12. Dhillon GS, Horch KW. Direct neural sensory feedback and control of a prosthetic arm. IEEE Transactions on Neural Systems and Rehabilitation Engineering 2005; 13:468-472. Published online: December 2005. DOI: 10.1109/TNSRE.2005.856072.

13. Collinger JL, Wodlinger B, Downey JE, Wang W, Tyler-Kabara EC, Weber DJ, et al. High-performance neuroprosthetic control by an individual with tetraplegia. The Lancet 2013; 381:557-564. Published online: February 16, 2013. DOI: 10.1016/S01406736(12)61816-9.

14. Warren DJ, Kellis S, Nieveen JG, Wendelken SM, Dantas H, Davis TS, et al. Recording and decoding for neural prostheses. Proceedings of the IEEE 2016; 104:374-391. Published online: February 2016. DOI: 10.1109/JPROC.2015.2507180.

15. Battye CK, Nightingale A, Whillis J. The use of myo-electric currents in the operation of prostheses. The Journal of Bone and Joint Surgery. British volume 1955; 37-B:506-510. Published online: August 1, 1955. DOI: 10.1302/0301-620X.37B3.506.

This article is protected by copyright. All rights reserved. 
16. Schultz AE, Kuiken TA. Neural Interfaces for Control of Upper Limb Prostheses: The State of the Art and Future Possibilities. PM\&R 2011; 3:55-67. Published online: January 2011. DOI: 10.1016/j.pmrj.2010.06.016.

17. Fougner A, Scheme E, Chan ADC, Englehart K, Stavdahl Ø. Resolving the Limb Position Effect in Myoelectric Pattern Recognition. IEEE Transactions on Neural Systems and Rehabilitation Engineering 2011; 19:644-651. Published online: December 2011. DOI: 10.1109/TNSRE.2011.2163529.

18. Young AJ, Hargrove LJ, Kuiken TA. The Effects of Electrode Size and Orientation on the Sensitivity of Myoelectric Pattern Recognition Systems to Electrode Shift. IEEE Transactions on Biomedical Engineering 2011; 58:2537-2544. Published online: September 2011. DOI: 10.1109/TBME.2011.2159216.

19. Muceli S, Jiang N, Farina D. Extracting Signals Robust to Electrode Number and Shift for Online Simultaneous and Proportional Myoelectric Control by Factorization Algorithms. IEEE Transactions on Neural Systems and Rehabilitation Engineering 2014; 22:623-633. Published online: May 2014. DOI: 10.1109/TNSRE.2013.2282898.

20. Stango A, Negro F, Farina D. Spatial Correlation of High Density EMG Signals Provides Features Robust to Electrode Number and Shift in Pattern Recognition for Myocontrol. IEEE Transactions on Neural Systems and Rehabilitation Engineering 2015; 23:189-198. Published online: March 2015. DOI: 10.1109/TNSRE.2014.2366752. 
21. Prahm C, Paassen B, Schulz A, Hammer B, Aszmann O. Transfer Learning for Rapid Recalibration of a Myoelectric Prosthesis After Electrode Shift. In: Ibáñez J, González-Vargas J, Azorín JM, Akay M, Pons JL, editors. Converging Clinical and Engineering Research on Neurorehabilitation II. Biosystems \& Biorobotics. Springer International Publishing: Cham; 2017. p. 153-157

22. Vidovic MM-C, Hwang H-J, Amsüss S, Hahne JM, Farina D, Müller K-R. Improving the Robustness of Myoelectric Pattern Recognition for Upper Limb Prostheses by Covariate Shift Adaptation. IEEE Transactions on Neural Systems and Rehabilitation Engineering 2016; 24:961-970. Published online: September 2016. DOI:

10.1109/TNSRE.2015.2492619.

23. Dhillon GS, Lawrence SM, Hutchinson DT, Horch KW. Residual function in peripheral nerve stumps of amputees: implications for neural control of artificial limbs1. The Journal of Hand Surgery 2004; 29:605-615. Published online: July 2004. DOI: 10.1016/j.jhsa.2004.02.006.

24. Jia X, Koenig MA, Zhang X, Zhang J, Chen T, Chen Z. Residual Motor Signal in LongTerm Human Severed Peripheral Nerves and Feasibility of Neural Signal-Controlled Artificial Limb. The Journal of Hand Surgery 2007; 32:657-666. Published online: May 2007. DOI: 10.1016/j.jhsa.2007.02.021.

This article is protected by copyright. All rights reserved. 
25. Clark GA, Ledbetter NM, Warren DJ, Harrison RR. Recording sensory and motor information from peripheral nerves with Utah Slanted Electrode Arrays. In: 2011 Annual International Conference of the IEEE Engineering in Medicine and Biology Society. 2011. p. $4641-4644$

26. Tyler DJ, Durand DM. Chronic Response of the Rat Sciatic Nerve to the Flat Interface Nerve Electrode. Annals of Biomedical Engineering 2003; 31:633-642. Published online: June 1, 2003. DOI: 10.1114/1.1569263.

27. Naples GG, Mortimer JT, Scheiner A, Sweeney JD. A spiral nerve cuff electrode for peripheral nerve stimulation. IEEE Transactions on Biomedical Engineering 1988; 35:905916. Published online: November 1988. DOI: 10.1109/10.8670.

28. Sahin M, Durand DM. Improved nerve cuff electrode recordings with subthreshold anodic currents. IEEE Transactions on Biomedical Engineering 1998; 45:1044-1050. Published online: August 1998. DOI: 10.1109/10.704873.

29. Popovic DB, Stein RB, Jovanovic KL, Dai R, Kostov A, Armstrong WW. Sensory nerve recording for closed-loop control to restore motor functions. IEEE Transactions on Biomedical Engineering 1993; 40:1024-1031. Published online: October 1993. DOI: 10.1109/10.247801. 
30. Sahin M, Haxhiu MA, Durand DM, Dreshaj IA. Spiral nerve cuff electrode for recordings of respiratory output. Journal of Applied Physiology 1997; 83:317-322. Published online: July 1, 1997.

31. Calvetti D, Wodlinger B, Durand DM, Somersalo E. Hierarchical beamformer and crosstalk reduction in electroneurography. Journal of Neural Engineering 2011; 8:056002. Published online: July 2011. DOI: 10.1088/1741-2560/8/5/056002.

32. Tang Y, Wodlinger B, Durand DM. Bayesian Spatial Filters for Source Signal Extraction: A Study in the Peripheral Nerve. IEEE Transactions on Neural Systems and Rehabilitation Engineering 2014; 22:302-311. Published online: March 2014. DOI: 10.1109/TNSRE.2014.2303472.

33. Wodlinger B, Durand DM. Localization and Recovery of Peripheral Neural Sources With Beamforming Algorithms. IEEE Transactions on Neural Systems and Rehabilitation Engineering 2009; 17:461-468. Published online: October 2009. DOI: 10.1109/TNSRE.2009.2034072.

34. Dweiri YM, Eggers TE, Gonzalez-Reyes LE, Drain J, McCallum GA, Durand DM. Stable Detection of Movement Intent From Peripheral Nerves: Chronic Study in Dogs. Proceedings of the IEEE 2017; 105:50-65. Published online: January 2017. DOI: 10.1109/JPROC.2016.2607520. 
35. Eggers TE, Dweiri YM, McCallum GA, Durand DM. Model-based Bayesian signal extraction algorithm for peripheral nerves. Journal of Neural Engineering 2017; 14:056009. Published online: August 2017. DOI: 10.1088/1741-2552/aa7d94.

36. Tyler DJ, Durand DM. Functionally selective peripheral nerve stimulation with a flat interface nerve electrode. IEEE Transactions on Neural Systems and Rehabilitation Engineering 2002; 10:294-303. Published online: December 2002. DOI: 10.1109/TNSRE.2002.806840.

37. Tan DW, Schiefer MA, Keith MW, Anderson JR, Tyler J, Tyler DJ. A neural interface provides long-term stable natural touch perception. Science Translational Medicine 2014; 6:257ra138-257ra138. Published online: October 8, 2014. DOI: 10.1126/scitranslmed.3008669.

38. Lawrence SM, Dhillon GS, Jensen W, Yoshida K, Horch KW. Acute Peripheral Nerve Recording Characteristics of Polymer-Based Longitudinal Intrafascicular Electrodes. IEEE Transactions on Neural Systems and Rehabilitation Engineering 2004; 12:345-348. Published online: September 2004. DOI: 10.1109/TNSRE.2004.831491.

39. Boretius T, Badia J, Pascual-Font A, Schuettler M, Navarro X, Yoshida K, et al. A transverse intrafascicular multichannel electrode (TIME) to interface with the peripheral nerve. Biosensors and Bioelectronics 2010; 26:62-69. Published online: September 15, 2010. DOI: 10.1016/j.bios.2010.05.010. 
40. Branner A, Stein RB, Normann RA. Selective Stimulation of Cat Sciatic Nerve Using an Array of Varying-Length Microelectrodes. Journal of Neurophysiology 2001; 85:15851594. Published online: April 1, 2001. DOI: 10.1152/jn.2001.85.4.1585.

41. Dhillon GS, Horch KW. Direct neural sensory feedback and control of a prosthetic arm. IEEE Transactions on Neural Systems and Rehabilitation Engineering 2005; 13:468-472. Published online: December 2005. DOI: 10.1109/TNSRE.2005.856072.

42. Horch K, Meek S, Taylor TG, Hutchinson DT. Object Discrimination With an Artificial Hand Using Electrical Stimulation of Peripheral Tactile and Proprioceptive Pathways With Intrafascicular Electrodes. IEEE Transactions on Neural Systems and Rehabilitation Engineering 2011; 19:483-489. Published online: October 2011. DOI: 10.1109/TNSRE.2011.2162635.

43. Micera S, Rossini PM, Rigosa J, Citi L, Carpaneto J, Raspopovic S, et al. Decoding of grasping information from neural signals recorded using peripheral intrafascicular interfaces. Journal of NeuroEngineering and Rehabilitation 2011; 8:53. Published online: September 5, 2011. DOI: 10.1186/1743-0003-8-53.

44. Rossini PM, Micera S, Benvenuto A, Carpaneto J, Cavallo G, Citi L, et al. Double nerve intraneural interface implant on a human amputee for robotic hand control. Clinical Neurophysiology 2010; 121:777-783. Published online: May 2010. DOI: 10.1016/j.clinph.2010.01.001. 
45. Raspopovic S, Capogrosso M, Petrini FM, Bonizzato M, Rigosa J, Pino GD, et al. Restoring Natural Sensory Feedback in Real-Time Bidirectional Hand Prostheses. Science Translational Medicine 2014; 6:222ra19-222ra19. Published online: February 5, 2014. DOI: 10.1126/scitranslmed.3006820.

46. George JA, Kluger DT, Davis TS, Wendelken SM, Okorokova EV, He Q, et al. Biomimetic sensory feedback through peripheral nerve stimulation improves dexterous use of a bionic hand. Science Robotics 2019; 4. Published online: July 24, 2019. DOI: 10.1126/scirobotics.aax2352.

47. Wendelken S, Page DM, Davis T, Wark HAC, Kluger DT, Duncan C, et al. Restoration of motor control and proprioceptive and cutaneous sensation in humans with prior upper-limb amputation via multiple Utah Slanted Electrode Arrays (USEAs) implanted in residual peripheral arm nerves. Journal of NeuroEngineering and Rehabilitation 2017; 14:121. Published online: November 25, 2017. DOI: 10.1186/s12984-017-0320-4.

48. Davis TS, Wark HAC, Hutchinson DT, Warren DJ, O’Neill K, Scheinblum T, et al. Restoring motor control and sensory feedback in people with upper extremity amputations using arrays of 96 microelectrodes implanted in the median and ulnar nerves. Journal of Neural Engineering 2016; 13:036001. Published online: 2016. DOI: 10.1088/17412560/13/3/036001. 
49. Christensen MB, Wark HAC, Hutchinson DT. A histological analysis of human median and ulnar nerves following implantation of Utah slanted electrode arrays. Biomaterials 2016; 77:235-242. Published online: January 1, 2016. DOI: 10.1016/j.biomaterials.2015.11.012.

50. Rossini PM, Micera S, Benvenuto A, Carpaneto J, Cavallo G, Citi L, et al. Double nerve intraneural interface implant on a human amputee for robotic hand control. Clinical Neurophysiology 2010; 121:777-783. Published online: May 1, 2010. DOI: 10.1016/j.clinph.2010.01.001.

51. Raspopovic S, Capogrosso M, Petrini FM, Bonizzato M, Rigosa J, Pino GD, et al. Restoring Natural Sensory Feedback in Real-Time Bidirectional Hand Prostheses. Science Translational Medicine 2014; 6:222ra19-222ra19. Published online: February 5, 2014. DOI: 10.1126/scitranslmed.3006820.

52. Kuiken TA, Dumanian GA, Lipschutz RD, Miller LA, Stubblefield KA. The use of targeted muscle reinnervation for improved myoelectric prosthesis control in a bilateral shoulder disarticulation amputee. Prosthetics and Orthotics International 2004; 28:245-253. Published online: December 1, 2004. DOI: 10.3109/03093640409167756.

53. Miller LA, Feuser AES, Kuiken TA. Targeted Muscle Reinnervation: A Neural Interface for Artificial Limbs. Taylor \& Francis, 2013. 
54. Dumanian GA, Potter BK, Mioton LM, Ko JH, Cheesborough JE, Souza JM, et al. Targeted Muscle Reinnervation Treats Neuroma and Phantom Pain in Major Limb Amputees: A Randomized Clinical Trial. Annals of Surgery 2019; Publish Ahead of Print. Published online: January 24, 2019. DOI: 10.1097/SLA.0000000000003088.

55. Kuiken, Li G, Lock BA, et al. Targeted muscle reinnervation for real-time myoelectric control of multifunction artificial arms. JAMA 2009; 301:619-628. Published online: February 11, 2009. DOI: 10.1001/jama.2009.116.

56. Zhou P, Lowery MM, Englehart KB, Huang H, Li G, Hargrove L, et al. Decoding a New Neural-Machine Interface for Control of Artificial Limbs. Journal of Neurophysiology 2007; 98:2974-2982. Published online: November 1, 2007. DOI: 10.1152/jn.00178.2007.

57. Hargrove LJ, Miller LA, Turner K, Kuiken TA. Myoelectric Pattern Recognition Outperforms Direct Control for Transhumeral Amputees with Targeted Muscle Reinnervation: A Randomized Clinical Trial. Scientific Reports 2017; 7:1-9. Published online: October 23, 2017. DOI: 10.1038/s41598-017-14386-w.

58. Cheesborough JE, Smith LH, Kuiken TA, Dumanian GA. Targeted Muscle Reinnervation and Advanced Prosthetic Arms. Seminars in Plastic Surgery 2015; 29:62-72. Published online: February 2015. DOI: 10.1055/s-0035-1544166.

This article is protected by copyright. All rights reserved. 
59. Delgado-Martínez I, Badia J, Pascual-Font A, Rodríguez-Baeza A, Navarro X. Fascicular Topography of the Human Median Nerve for Neuroprosthetic Surgery. Frontiers in Neuroscience 2016; 10. Published online: July 1, 2016. DOI: 10.3389/fnins.2016.00286.

60. Stubblefield KA, Miller LA, Lipschutz RD, Kuiken TA. Occupational therapy protocol for amputees with targeted muscle reinnervation. Journal of rehabilitation research and development 2009; 46:481-488. Published online: 2009.

61. Urbanchek MG, Kung TA, Frost CM, Martin DC, Larkin LM, Wollstein A, et al. Development of a Regenerative Peripheral Nerve Interface for Control of a Neuroprosthetic Limb. BioMed Research International 2016; 2016:1-8. Published online: 2016. DOI: $10.1155 / 2016 / 5726730$.

62. Kubiak CA, Kemp SWP, Cederna PS. Regenerative Peripheral Nerve Interface for Management of Postamputation Neuroma. JAMA Surgery 2018; 153:681-682. Published online: July 1, 2018. DOI: 10.1001/jamasurg.2018.0864.

63. Kubiak CA, Kemp SWP, Cederna PS, Kung TA. Prophylactic Regenerative Peripheral Nerve Interfaces to Prevent Postamputation Pain. Plastic and Reconstructive Surgery 2019; 144:421e. Published online: September 2019. DOI: 10.1097/PRS.0000000000005922. 
64. Urbanchek MG, Baghmanli Z, Moon JD, Sugg KB, Langhals NB, Cederna PS. Quantification of Regenerative Peripheral Nerve Interface Signal Transmission. Plastic and Reconstructive Surgery 2012; 130. Published online: 2012.

65. Kung TA, Langhals NB, Martin DC, Johnson PJ, Cederna PS, Urbanchek MG. Regenerative Peripheral Nerve Interface Viability and Signal Transduction with an Implanted Electrode. Plastic and Reconstructive Surgery 2014; 133. Published online: 2014.

66. Ursu DC, Urbanchek MG, Nedic A, Cederna PS, Gillespie RB. In vivo characterization of regenerative peripheral nerve interface function. Journal of Neural Engineering 2016; 13:026012. Published online: April 1, 2016. DOI: 10.1088/1741-2560/13/2/026012.

67. Irwin ZT, Schroeder KE, Vu PP, Tat DM, Bullard AJ, Woo SL, et al. Chronic recording of hand prosthesis control signals via a regenerative peripheral nerve interface in a rhesus macaque. Journal of Neural Engineering 2016; 13:046007. Published online: June 2016. DOI: $10.1088 / 1741-2560 / 13 / 4 / 046007$.

68. Vu PP, Irwin ZT, Bullard AJ, Ambani SW, Sando IC, Urbanchek MG, et al. Closed-Loop Continuous Hand Control via Chronic Recording of Regenerative Peripheral Nerve Interfaces. IEEE Transactions on Neural Systems and Rehabilitation Engineering 2018; 26:515-526. Published online: February 2018. DOI: 10.1109/TNSRE.2017.2772961. 
69. Vu PP, Vaskov AK, Irwin ZT, Henning PT, Lueders DR, Laidlaw AT, et al. A regenerative peripheral nerve interface allows real-time control of an artificial hand in upper limb amputees. Science Translational Medicine December 2019. Published online: December 2019.

70. Anderson KD. Targeting Recovery: Priorities of the Spinal Cord-Injured Population. Journal of Neurotrauma 2004; 21:1371-1383. Published online: October 1, 2004. DOI: 10.1089/neu.2004.21.1371.

71. Blabe CH, Gilja V, Chestek CA, Shenoy KV, Anderson KD, Henderson JM. Assessment of brain-machine interfaces from the perspective of people with paralysis. Journal of Neural Engineering 2015; 12:043002. Published online: July 2015. DOI: 10.1088/17412560/12/4/043002.

72. Peckham PH, Knutson JS. Functional Electrical Stimulation for Neuromuscular Applications. Annual Review of Biomedical Engineering 2005; 7:327-360. Published online: 2005. DOI: 10.1146/annurev.bioeng.6.040803.140103.

73. Peckham PH, Mortimer JT, Marsolais EB. Controlled prehension and release in the C5 quadriplegic elicited by functional electrical stimulation of the paralyzed forearm musculature. Annals of Biomedical Engineering 1980; 8:369-388. Published online: July 1, 1980. DOI: $10.1007 / \mathrm{BF} 02363440$. 
74. Kilgore KL, Peckham PH, Thrope GB, Keith MW, Gallaher-Stone KA. Synthesis of hand grasp using functional neuromuscular stimulation. IEEE Transactions on Biomedical Engineering 1989; 36:761-770. Published online: July 1989. DOI: 10.1109/10.32109.

75. Peckham PH, Keith MW, Kilgore KL, Grill JH, Wuolle KS, Thrope GB, et al. Efficacy of an implanted neuroprosthesis for restoring hand grasp in tetraplegia: A multicenter study. Archives of Physical Medicine and Rehabilitation 2001; 82:1380-1388. Published online: October 1, 2001. DOI: 10.1053/apmr.2001.25910.

76. Kilgore KL, Hoyen HA, Bryden AM, Hart RL, Keith MW, Peckham PH. An Implanted Upper-Extremity Neuroprosthesis Using Myoelectric Control. The Journal of Hand Surgery 2008; 33:539-550. Published online: April 1, 2008. DOI: 10.1016/j.jhsa.2008.01.007.

77. Krusienski DJ, Sellers EW, Cabestaing F, Bayoudh S, McFarland DJ, Vaughan TM, et al. A comparison of classification techniques for the P300 Speller. Journal of Neural Engineering 2006; 3:299-305. Published online: October 2006. DOI: 10.1088/17412560/3/4/007.

78. Edelman BJ, Meng J, Suma D, Zurn C, Nagarajan E, Baxter BS, et al. Noninvasive neuroimaging enhances continuous neural tracking for robotic device control. Science Robotics 2019; 4. Published online: June 19, 2019. DOI: 10.1126/scirobotics.aaw6844. 
79. Leuthardt EC, Schalk G, Wolpaw JR, Ojemann JG, Moran DW. A brain-computer interface using electrocorticographic signals in humans. Journal of Neural Engineering 2004; 1:63-71. Published online: June 2004. DOI: 10.1088/1741-2560/1/2/001.

80. Schalk G, Miller KJ, Anderson NR, Wilson JA, Smyth MD, Ojemann JG, et al. Twodimensional movement control using electrocorticographic signals in humans. Journal of Neural Engineering 2008; 5:75-84. Published online: February 2008. DOI: 10.1088/17412560/5/1/008.

81. Kubánek J, Miller KJ, Ojemann JG, Wolpaw JR, Schalk G. Decoding flexion of individual fingers using electrocorticographic signals in humans. Journal of Neural Engineering 2009; 6:066001. Published online: October 2009. DOI: 10.1088/1741-2560/6/6/066001.

82. Pistohl T, Schulze-Bonhage A, Aertsen A, Mehring C, Ball T. Decoding natural grasp types from human ECoG. NeuroImage 2012; 59:248-260. Published online: January 2, 2012. DOI: 10.1016/j.neuroimage.2011.06.084.

83. Chestek CA, Gilja V, Blabe CH, Foster BL, Shenoy KV, Parvizi J, et al. Hand posture classification using electrocorticography signals in the gamma band over human sensorimotor brain areas. Journal of Neural Engineering 2013; 10:026002. Published online: January 2013. DOI: 10.1088/1741-2560/10/2/026002. 
84. Hotson G, McMullen DP, Fifer MS, Johannes MS, Katyal KD, Para MP, et al. Individual finger control of a modular prosthetic limb using high-density electrocorticography in a human subject. Journal of Neural Engineering 2016; 13:026017. Published online: February 2016. DOI: 10.1088/1741-2560/13/2/026017.

85. Flint RD, Rosenow JM, Tate MC, Slutzky MW. Continuous decoding of human grasp kinematics using epidural and subdural signals. Journal of Neural Engineering 2016; 14:016005. Published online: November 2016. DOI: 10.1088/1741-2560/14/1/016005.

86. Schmidt RA. Motor program utilization over extended practice. Journal of Human Movement Studies 1976; 2:239-247. Published online: 1976.

87. Campbell PK, Jones KE, Huber RJ, Horch KW, Normann RA. A silicon-based, threedimensional neural interface: manufacturing processes for an intracortical electrode array. IEEE Transactions on Biomedical Engineering 1991; 38:758-768. Published online: August 1991. DOI: 10.1109/10.83588.

88. Nordhausen CT, Maynard EM, Normann RA. Single unit recording capabilities of a 100 microelectrode array. Brain Research 1996; 726:129-140. Published online: July 8, 1996. DOI: 10.1016/0006-8993(96)00321-6. 
89. Normann RA, Maynard EM, Rousche PJ, Warren DJ. A neural interface for a cortical vision prosthesis. Vision Research 1999; 39:2577-2587. Published online: July 1, 1999. DOI: 10.1016/S0042-6989(99)00040-1.

90. Nicolelis MAL, Ghazanfar AA, Faggin BM, Votaw S, Oliveira LMO. Reconstructing the Engram: Simultaneous, Multisite, Many Single Neuron Recordings. Neuron 1997; 18:529537. Published online: April 1, 1997. DOI: 10.1016/S0896-6273(00)80295-0.

91. Musallam S, Bak MJ, Troyk PR, Andersen RA. A floating metal microelectrode array for chronic implantation. Journal of Neuroscience Methods 2007; 160:122-127. Published online: February 15, 2007. DOI: 10.1016/j.jneumeth.2006.09.005.

92. Patel PR, Zhang H, Robbins MT, Nofar JB, Marshall SP, Kobylarek MJ, et al. Chronicin vivostability assessment of carbon fiber microelectrode arrays. Journal of Neural Engineering 2016; 13:066002. Published online: October 2016. DOI: 10.1088/17412560/13/6/066002.

93. Carmena JM, Lebedev MA, Henriquez CS, Nicolelis MAL. Stable Ensemble Performance with Single-Neuron Variability during Reaching Movements in Primates. Journal of Neuroscience 2005; 25:10712-10716. Published online: November 16, 2005. DOI: 10.1523/JNEUROSCI.2772-05.2005. 
94. Suminski AJ, Tkach DC, Fagg AH, Hatsopoulos NG. Incorporating Feedback from Multiple Sensory Modalities Enhances Brain-Machine Interface Control. Journal of Neuroscience 2010; 30:16777-16787. Published online: December 15, 2010. DOI: 10.1523/JNEUROSCI.3967-10.2010.

95. Hochberg LR, Bacher D, Jarosiewicz B, Masse NY, Simeral JD, Vogel J, et al. Reach and grasp by people with tetraplegia using a neurally controlled robotic arm. Nature 2012; 485:372-375. Published online: May 2012. DOI: 10.1038/nature11076.

96. Moritz CT, Perlmutter SI, Fetz EE. Direct control of paralysed muscles by cortical neurons. Nature 2008; 456:639-642. Published online: December 2008. DOI: 10.1038/nature07418.

97. Ethier C, Oby ER, Bauman MJ, Miller LE. Restoration of grasp following paralysis through brain-controlled stimulation of muscles. Nature 2012; 485:368-371. Published online: May 2012. DOI: $10.1038 /$ nature10987.

98. Capogrosso M, Milekovic T, Borton D, Wagner F, Moraud EM, Mignardot J-B, et al. A brain-spine interface alleviating gait deficits after spinal cord injury in primates. Nature 2016; 539:284-288. Published online: November 2016. DOI: 10.1038/nature20118.

99. Bouton CE, Shaikhouni A, Annetta NV, Bockbrader MA, Friedenberg DA, Nielson DM, et al. Restoring cortical control of functional movement in a human with quadriplegia. Nature 2016; 533:247-250. Published online: May 2016. DOI: 10.1038/nature17435.

This article is protected by copyright. All rights reserved. 
100. Ajiboye AB, Willett FR, Young DR, Memberg WD, Murphy BA, Miller JP, et al. Restoration of reaching and grasping movements through brain-controlled muscle stimulation in a person with tetraplegia: a proof-of-concept demonstration. The Lancet 2017; 389:1821-1830. Published online: May 6, 2017. DOI: 10.1016/S01406736(17)30601-3.

101. Irwin ZT, Schroeder KE, Vu PP, Bullard AJ, Tat DM, Nu CS, et al. Neural control of finger movement via intracortical brain-machine interface. Journal of Neural Engineering 2017; 14:066004. Published online: November 2017. DOI: 10.1088/1741-2552/aa80bd.

102. Vaskov AK, Irwin ZT, Nason SR, Vu PP, Nu CS, Bullard AJ, et al. Cortical Decoding of Individual Finger Group Motions Using ReFIT Kalman Filter. Frontiers in Neuroscience 2018; 12. Published online: 2018. DOI: 10.3389/fnins.2018.00751.

103. Hudgins B, Parker P, Scott RN. A new strategy for multifunction myoelectric control. IEEE Transactions on Biomedical Engineering 1993; 40:82-94. Published online: January 1993. DOI: $10.1109 / 10.204774$.

104. Hamed SB, Schieber MH, Pouget A. Decoding M1 Neurons During Multiple Finger Movements. Journal of Neurophysiology 2007; 98:327-333. Published online: July 1, 2007. DOI: 10.1152/jn.00760.2006. 
105. Egan J, Baker J, House PA, Greger B. Decoding Dexterous Finger Movements in a Neural Prosthesis Model Approaching Real-World Conditions. IEEE Transactions on Neural Systems and Rehabilitation Engineering 2012; 20:836-844. Published online: November 2012. DOI: 10.1109/TNSRE.2012.2210910.

106. Ajiboye AB, Weir RF. A heuristic fuzzy logic approach to EMG pattern recognition for multifunctional prosthesis control. IEEE Transactions on Neural Systems and Rehabilitation Engineering 2005; 13:280-291. Published online: September 2005. DOI: 10.1109/TNSRE.2005.847357.

107. Tsenov G, Zeghbib AH, Palis F, Shoylev N, Mladenov V. Neural Networks for Online Classification of Hand and Finger Movements Using Surface EMG signals. In: 2006 8th Seminar on Neural Network Applications in Electrical Engineering. 2006. p. 167-171

108. Hargrove LJ, Miller LA, Turner K, Kuiken TA. Myoelectric Pattern Recognition Outperforms Direct Control for Transhumeral Amputees with Targeted Muscle Reinnervation: A Randomized Clinical Trial. Scientific Reports 2017; 7:13840. Published online: October 23, 2017. DOI: 10.1038/s41598-017-14386-w.

109. Barsotti M, Dupan S, Vujaklija I, Došen S, Frisoli A, Farina D. Online Finger Control Using High-Density EMG and Minimal Training Data for Robotic Applications. IEEE Robotics and Automation Letters 2019; 4:217-223. Published online: April 2019. DOI: 10.1109/LRA.2018.2885753.

This article is protected by copyright. All rights reserved. 
110. Hahne JM, Biebmann F, Jiang N, Rehbaum H, Farina D, Meinecke FC, et al. Linear and Nonlinear Regression Techniques for Simultaneous and Proportional Myoelectric Control. IEEE Transactions on Neural Systems and Rehabilitation Engineering 2014; 22:269-279. Published online: March 2014. DOI: 10.1109/TNSRE.2014.2305520.

111. Jiang N, Rehbaum H, Vujaklija I, Graimann B, Farina D. Intuitive, Online, Simultaneous, and Proportional Myoelectric Control Over Two Degrees-of-Freedom in Upper Limb Amputees. IEEE Transactions on Neural Systems and Rehabilitation Engineering 2014; 22:501-510. Published online: May 2014. DOI: 10.1109/TNSRE.2013.2278411.

112. Nielsen JLG, Holmgaard S, Jiang N, Englehart KB, Farina D, Parker PA. Simultaneous and Proportional Force Estimation for Multifunction Myoelectric Prostheses Using Mirrored Bilateral Training. IEEE Transactions on Biomedical Engineering 2011; 58:681-688. Published online: March 2011. DOI: 10.1109/TBME.2010.2068298.

113. Smith LH, Kuiken TA, Hargrove LJ. Use of probabilistic weights to enhance linear regression myoelectric control. Journal of Neural Engineering 2015; 12:066030. Published online: 2015. DOI: 10.1088/1741-2560/12/6/066030.

114. Wu W, Gao Y, Bienenstock E, Donoghue JP, Black MJ. Bayesian Population Decoding of Motor Cortical Activity Using a Kalman Filter. Neural Computation 2006; 18:80-118. Published online: January 1, 2006. DOI: 10.1162/089976606774841585. 
115. Davis TS, Wark HAC, Hutchinson DT, Warren DJ, O’Neill K, Scheinblum T, et al. Restoring motor control and sensory feedback in people with upper extremity amputations using arrays of 96 microelectrodes implanted in the median and ulnar nerves. Journal of Neural Engineering 2016; 13:036001. Published online: March 2016. DOI: 10.1088/17412560/13/3/036001.

116. Farina D, Negro F. Accessing the Neural Drive to Muscle and Translation to Neurorehabilitation Technologies. IEEE Reviews in Biomedical Engineering 2012; 5:3-14. Published online: 2012. DOI: 10.1109/RBME.2012.2183586.

117. Heckman CJ, Enoka RM. Physiology of the motor neuron and the motor unit. In: Eisen A, editor. Handbook of Clinical Neurophysiology. Vol 4. Clinical Neurophysiology of Motor Neuron Diseases. Elsevier; 2004. p. 119-147 http://www.sciencedirect.com/science/article/pii/S1567423104040067. Accessed January 29, 2019.

118. Morrow MM, Miller LE. Prediction of Muscle Activity by Populations of Sequentially Recorded Primary Motor Cortex Neurons. Journal of Neurophysiology 2003; 89:22792288. Published online: April 1, 2003. DOI: 10.1152/jn.00632.2002.

119. Pohlmeyer EA, Solla SA, Perreault EJ, Miller LE. Prediction of upper limb muscle activity from motor cortical discharge during reaching. Journal of Neural Engineering 2007; 4:369379. Published online: November 2007. DOI: 10.1088/1741-2560/4/4/003. 
120. Buchanan TS, Lloyd DG, Manal K, Besier TF. Neuromusculoskeletal Modeling: Estimation of Muscle Forces and Joint Moments and Movements from Measurements of Neural Command. Journal of Applied Biomechanics 2004; 20:367-395. Published online: November 1, 2004. DOI: 10.1123/jab.20.4.367.

121. Sartori M, Farina D, Lloyd DG. Hybrid neuromusculoskeletal modeling to best track joint moments using a balance between muscle excitations derived from electromyograms and optimization. Journal of Biomechanics 2014; 47:3613-3621. Published online: November 28, 2014. DOI: 10.1016/j.jbiomech.2014.10.009.

122. Sartori M, Durandau G, Došen S, Farina D. Robust simultaneous myoelectric control of multiple degrees of freedom in wrist-hand prostheses by real-time neuromusculoskeletal modeling. Journal of Neural Engineering 2018; 15:066026. Published online: October 2018. DOI: 10.1088/1741-2552/aae26b.

123. Yu BM, Cunningham JP, Santhanam G, Ryu SI, Shenoy KV, Sahani M. Gaussian-process factor analysis for low-dimensional single-trial analysis of neural population activity. In: Koller D, Schuurmans D, Bengio Y, Bottou L, editors. Advances in Neural Information Processing Systems 21. Curran Associates, Inc.; 2009. p. 1881-1888 http://papers.nips.cc/paper/3494-gaussian-process-factor-analysis-for-low-dimensionalsingle-trial-analysis-of-neural-population-activity.pdf. Accessed November 27, 2019. 
124. Churchland MM, Cunningham JP, Kaufman MT, Foster JD, Nuyujukian P, Ryu SI, et al. Neural population dynamics during reaching. Nature 2012; 487:51-56. Published online: July 2012. DOI: 10.1038/nature11129.

125. Pandarinath C, O’Shea DJ, Collins J, Jozefowicz R, Stavisky SD, Kao JC, et al. Inferring single-trial neural population dynamics using sequential auto-encoders. Nature Methods 2018; 15:805-815. Published online: October 2018. DOI: 10.1038/s41592-018-0109-9.

126. Trautmann EM, Stavisky SD, Lahiri S, Ames KC, Kaufman MT, O’Shea DJ, et al. Accurate Estimation of Neural Population Dynamics without Spike Sorting. Neuron 2019; 103:292-308.e4. Published online: July 17, 2019. DOI: 10.1016/j.neuron.2019.05.003.

127. Ripple Neuro. Grapevine Research System User Manual. https://s3-us-west2.amazonaws.com/rippleneuro/downloads/Grapevine_User_Manual_v16.pdf. Accessed February 11, 2020.

128. Pasquina PF, Evangelista M, Carvalho AJ, Lockhart J, Griffin S, Nanos G, et al. First-inman demonstration of a fully implanted myoelectric sensors system to control an advanced electromechanical prosthetic hand. Journal of Neuroscience Methods 2015; 244:85-93. Published online: April 15, 2015. DOI: 10.1016/j.jneumeth.2014.07.016. 
129. Borton DA, Yin M, Aceros J, Nurmikko A. An implantable wireless neural interface for recording cortical circuit dynamics in moving primates. Journal of Neural Engineering 2013; 10:026010. Published online: February 2013. DOI: 10.1088/1741-2560/10/2/026010.

130. Cleveland FES Center | Networked Neuroprosthetic (NNP) System. http://fescenter.org/research/technology-programs/networked-neuroprosthetic-systemnnps/. Accessed February 11, 2020.

131. Polasek KH, Schiefer MA, Pinault GCJ, Triolo RJ, Tyler DJ. Intraoperative evaluation of the spiral nerve cuff electrode on the femoral nerve trunk. Journal of Neural Engineering 2009; 6:066005. Published online: November 2009. DOI: 10.1088/1741-2560/6/6/066005.

132. Kim S-J, Manyam SC, Warren DJ, Normann RA. Electrophysiological Mapping of Cat Primary Auditory Cortex with Multielectrode Arrays. Annals of Biomedical Engineering 2006; 34:300-309. Published online: February 1, 2006. DOI: 10.1007/s10439-005-9037-9. 
Figure. 1 Diagram of a brain machine interface system with functional electrical stimulation and a peripheral nerve interface system. (A) A brain machine interface records signals directly from the brain. The signals are then interpreted to predict the user's intentional movement. Stimulation of the muscles (functional electrical stimulation) executes the predicted movement. (B) A peripheral nerve interface records signals from the nerves. Like brain signals, the nerve signals are also decoded to decipher the user's intention. For patients with amputations, the predicted movement is sent to an artificial prosthesis.

Figure 2 Different types of electrodes have been made to interface directly with the peripheral nerve. The most common electrode types are the cuff electrode (top) and the Utah Slanted electrode array (bottom). With the cuff electrode recording from a population of nerve fascicles and the Utah slanted array recording directly from nerve fascicles, the resolution of the nerve signals differs between each interface. Cuff electrode picture and signals were adapted from Polasek et al., 2009 and Sahin et al., 1997, respectively. ${ }^{30,131}$ Utah slanted electrode array picture and signals were adapted from Branner et al., 2001 and Warren et al., 2016, respectively. ${ }^{14,40}$

Figure 3 Examples of surgical techniques to help improve peripheral interfaces. (A) Targeted muscle reinnervation involves re-routing the nerves to intact muscles following amputation. The nerves reinnervate the "target" muscle, allowing signal transmission from that muscle, to provide control signals for a missing arm or hand. (B) Regenerative peripheral nerve interfaces (RPNIs) are created by implanting the end of a divided peripheral nerve, or nerve fascicle, into a free skeletal muscle graft. The 
RPNIs can then be used to amplify the efferent motor action potentials. Independent control signals can then be extracted to control a prosthesis from each of the RPNIs.

Figure 4 Various types of electrodes have been made to interface directly with the brain. The most common invasive electrode types are electrocorticography (EcoG) electrodes (left), and the Utah electrode array and floating microelectrode array (right). Similar to how certain types of peripheral nerve electrodes record different signal resolutions, various types of brain electrodes also extract different signal resolutions. EcoG electrodes record local field potentials, whereas Utah electrode arrays can record extracellular action potentials from individual neurons. EcoG electrodes and signals were adapted from Leuthardt et al., 2004. ${ }^{79}$ Floating microelectrode array picture and Utah slanted array pictures adapted from Microprobes and Kim et al., 2006. ${ }^{132}$

Figure 5 Discrete and continuous control methods. (A) Discrete control methods interpret patterns from neural signals and then chooses a specific posture or movement associated with that pattern. The predicted posture is then transmitted to the prosthesis. (B) Unlike discrete control, continuous control can continuously predict multiple postures at once. For example, a user could flex the wrist and close the hand at the same time, or extend the wrist and open the hand.

Figure 6 Example of a portable functional electrical stimulation system for clinical use. All modules would be surgically implanted to achieve full device portability. Illustration adapted from Case Western Reserve University/Synapse Biomedical Inc.. 


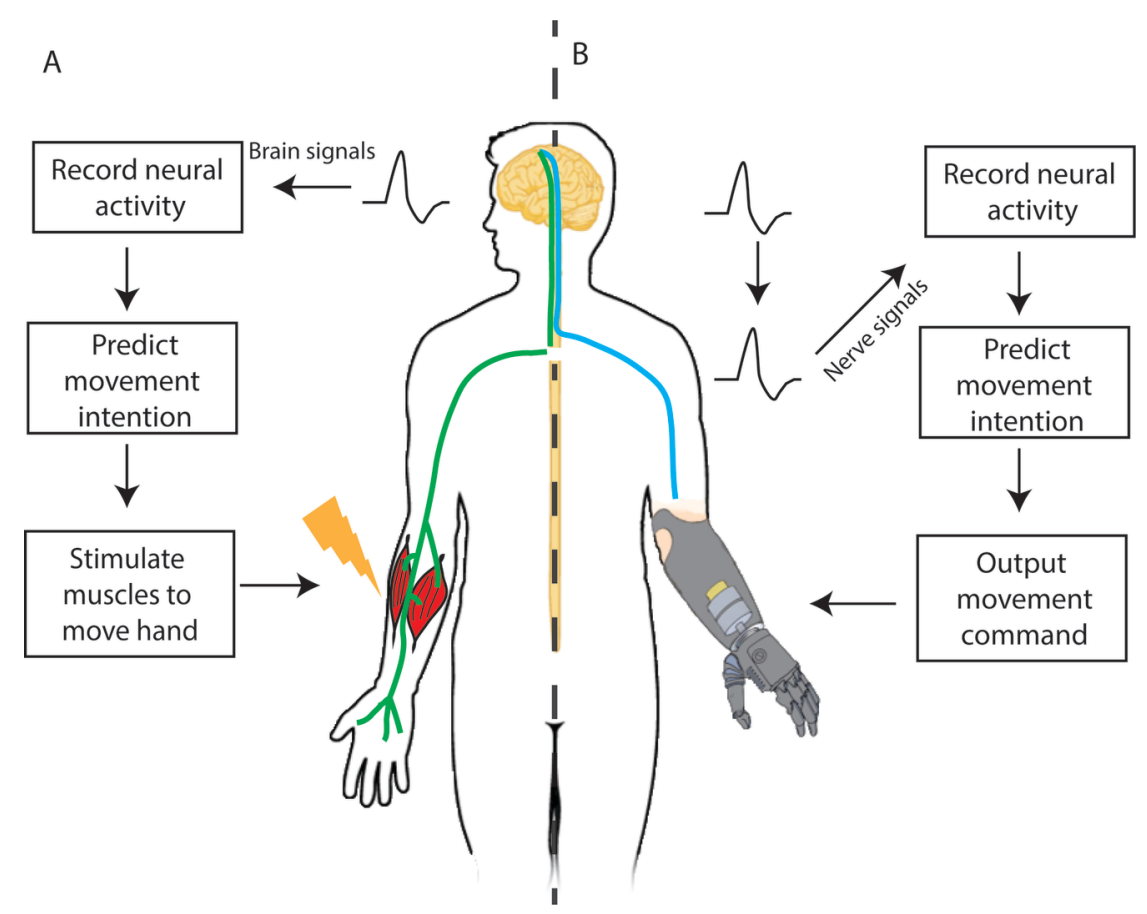

MUS_26860_Figure 1 compressed.tif

This article is protected by copyright. All rights reserved. 


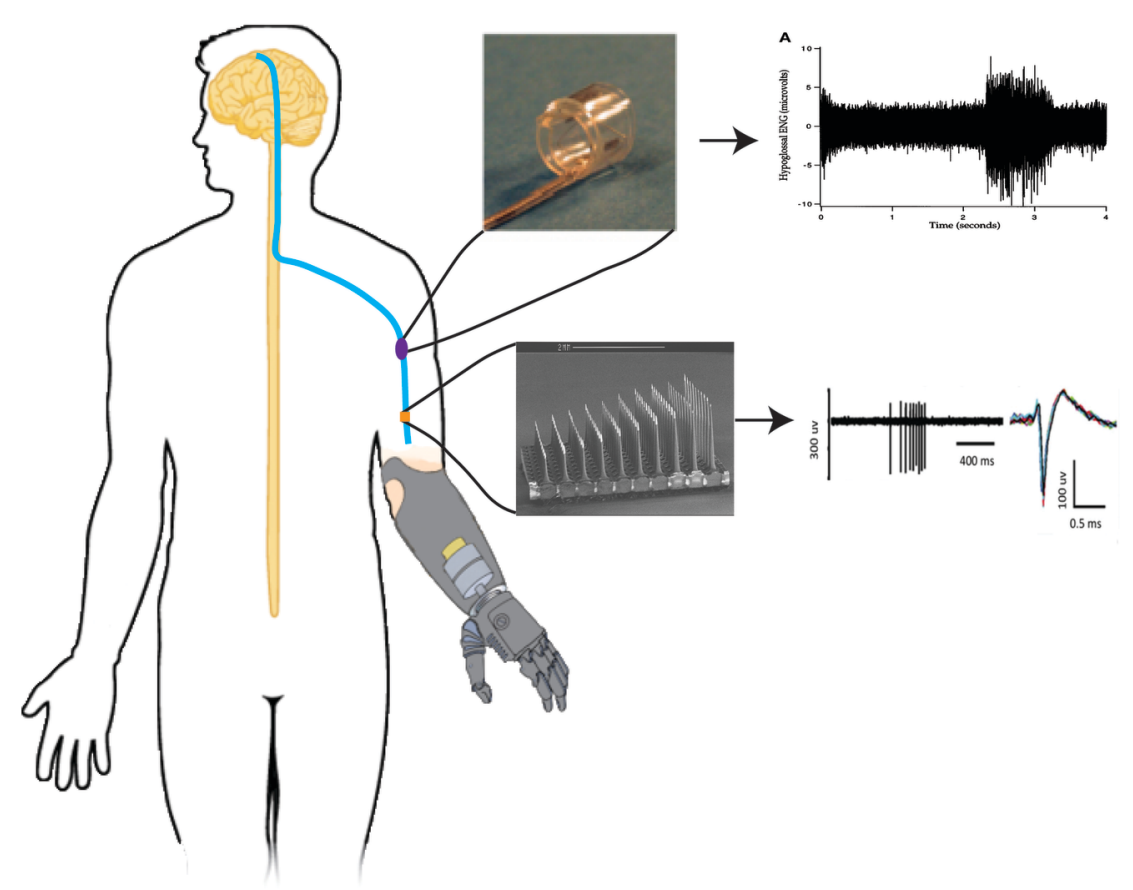

MUS_26860_Figure 2 compressed.tif 
A

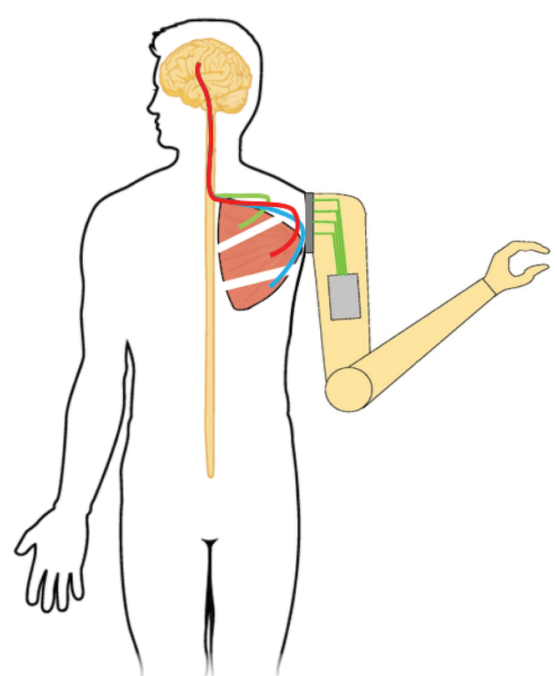

B

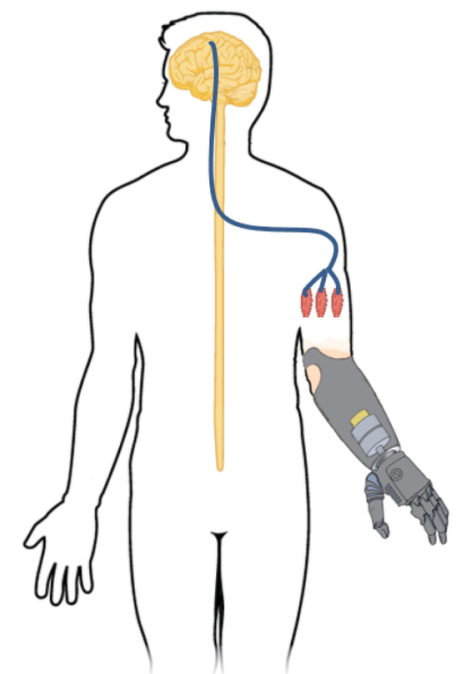

MUS_26860_Figure 3 compressed.tif

This article is protected by copyright. All rights reserved. 


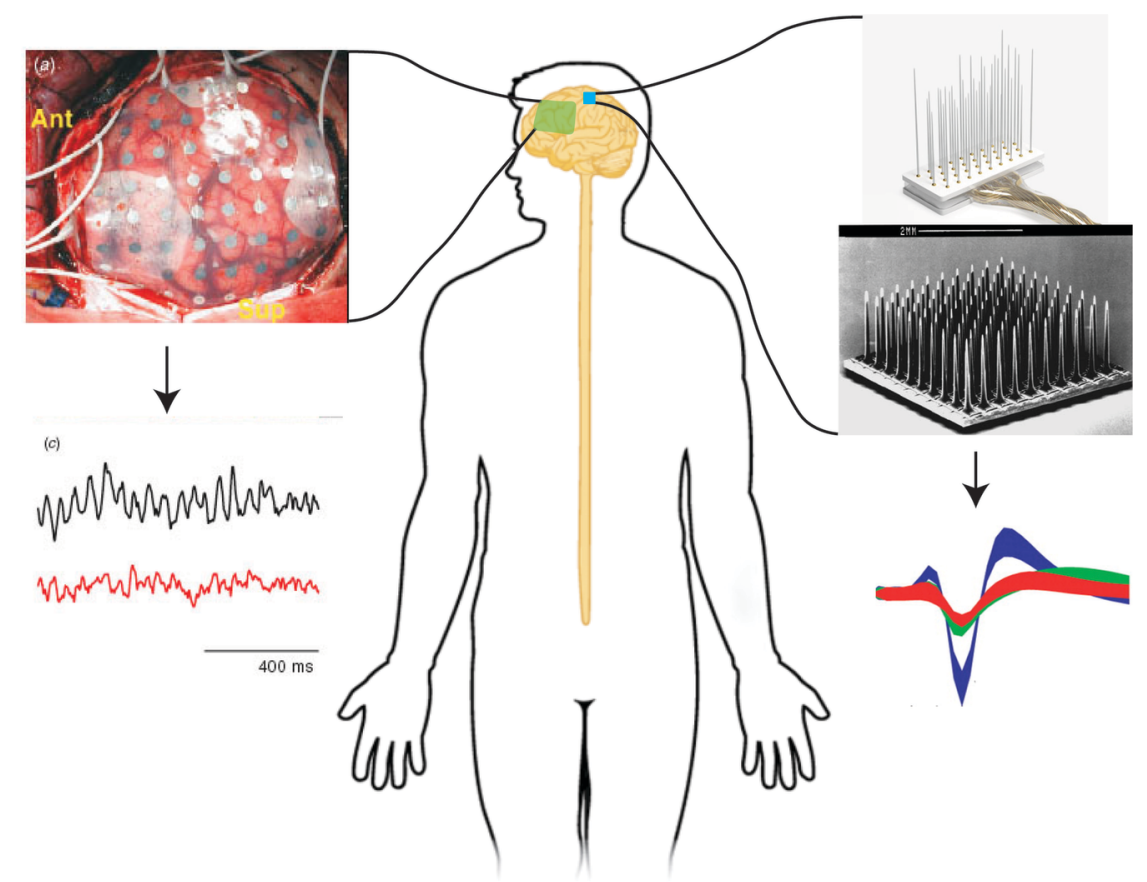

MUS_26860_Figure 4 compressed.tif 
A

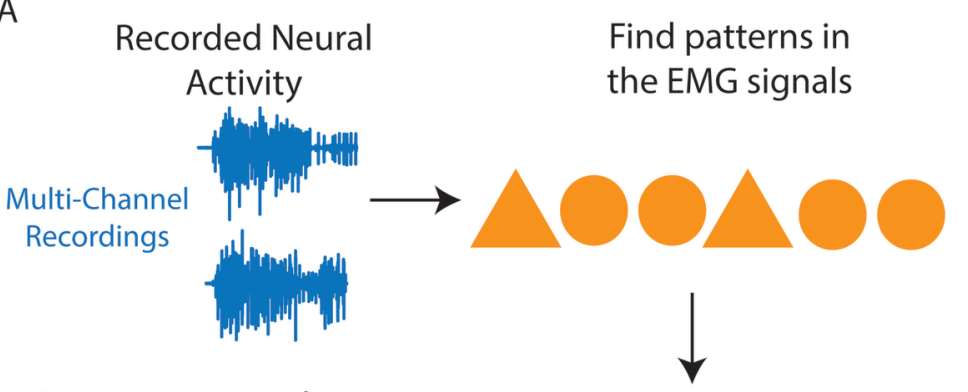

Output command to prosthesis

Choose a movement

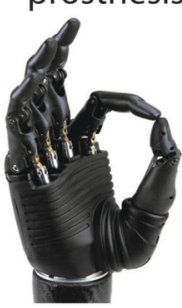
associated with the pattern

B

Recorded Neura

Continuous and Activity

Simultaneous control

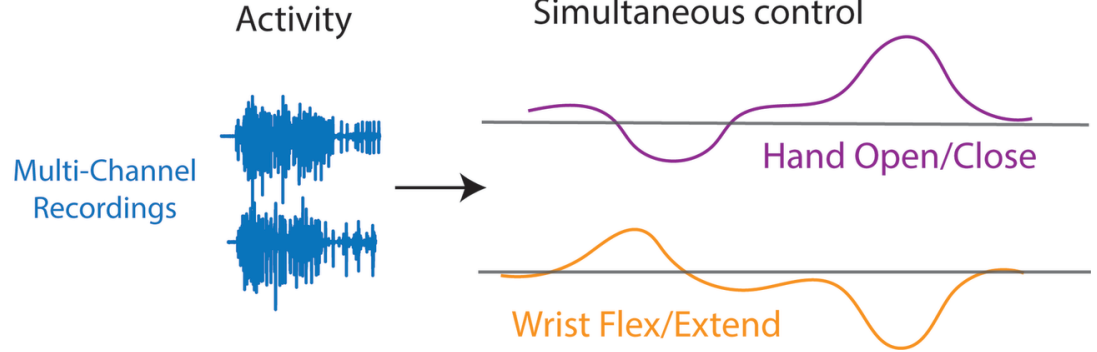

MUS_26860_Figure 5 compressed.tif

This article is protected by copyright. All rights reserved. 


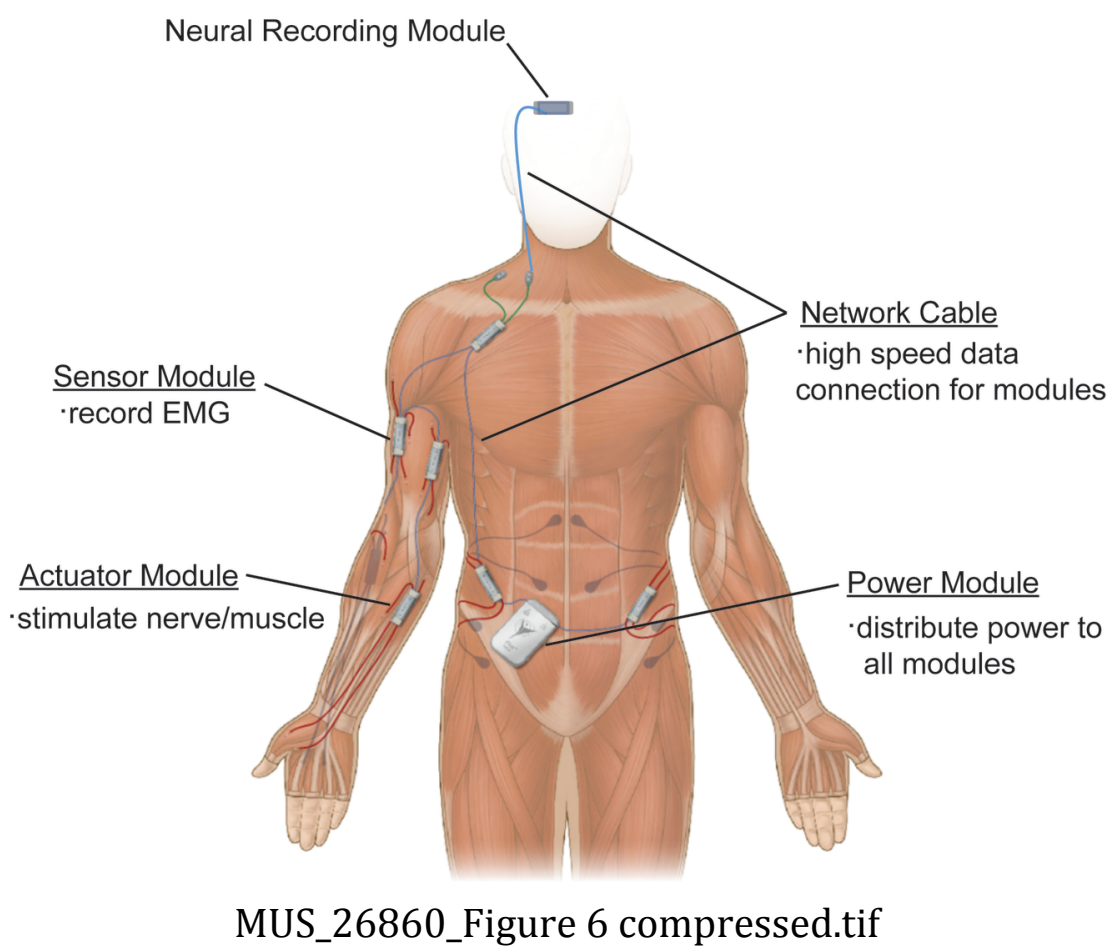

This article is protected by copyright. All rights reserved. 